University of Nebraska - Lincoln

DigitalCommons@University of Nebraska - Lincoln

Faculty Publications, Department of Psychology

Psychology, Department of

2010

Iptakalim: A Potential Antipsychotic Drug with Novel

Mechanisms?

Tao Sun

Nanjing Medical University, PR China

Changjiu Zhao

University of Nebraska-Lincoln, czhao2@unl.edu

Gang Hu

Nanjing Medical University, PR China

Ming Li

University of Nebraska-Lincoln, mli2@unl.edu

Follow this and additional works at: https://digitalcommons.unl.edu/psychfacpub

Part of the Psychiatry and Psychology Commons

Sun, Tao; Zhao, Changjiu; Hu, Gang; and Li, Ming, "Iptakalim: A Potential Antipsychotic Drug with Novel Mechanisms?" (2010). Faculty Publications, Department of Psychology. 489.

https://digitalcommons.unl.edu/psychfacpub/489

This Article is brought to you for free and open access by the Psychology, Department of at DigitalCommons@University of Nebraska - Lincoln. It has been accepted for inclusion in Faculty Publications, Department of Psychology by an authorized administrator of DigitalCommons@University of Nebraska - Lincoln. 
Published in European Journal of Pharmacology 634:1-3 (May 25, 2010), pp. 68-76; doi: 10.1016/j.ejphar.2010.02.024 Copyright $\odot$ 2010 Elsevier B.V. Used by permission.

\title{
Iptakalim: A Potential Antipsychotic Drug with Novel Mechanisms?
}

\author{
Tao Sun, ${ }^{1,2}$ Changjiu Zhao, ${ }^{2}$ Gang $\mathrm{Hu},{ }^{1}$ and Ming $\mathrm{Li}^{2}$ \\ ${ }^{1}$ Jiangsu Key Laboratory of Neurodegeneration, Department of Pharmacology, Nanjing Medical University, PR China \\ ${ }^{2}$ Department of Psychology, University of Nebraska-Lincoln, USA
}

Corresponding author - Ming Li, 238 Burnett Hall, Department of Psychology, University of Nebraska-Lincoln, Lincoln, NE 68588-0308, USA; tel 402 472-3144, email mli2@unl.edu

\begin{abstract}
Iptakalim is a novel putative adenosine triphosphate (ATP)-sensitive potassium $\left(\mathrm{K}_{\mathrm{ATP}}\right)$ channel opener. In the brain, iptakalim is thought to act on the neuronal and astrocytic plasma membrane and/or mitochondrial $\mathrm{K}_{\mathrm{ATP}}$ channels. Because iptakalim demonstrates an action on the regulation of dopamine and glutamate release in the forebrain regions, we examined its potential antipsychotic efficacy in several preclinical tests. First, we show that iptakalim is effective in reducing amphetamine- and phencyclidine-induced hyperlocomotion as well as selectively disrupting conditioned avoidance responding. Next, we show that combined iptakalim and amphetamine treatment produces a reduction on prepulse inhibition of acoustic startle and this combined drug effect is also found with haloperidol, but not with clozapine. Finally, we show that iptakalim and clozapine preferentially increase c-Fos expression in the medial prefrontal cortex, nucleus accumbens and lateral septal nucleus, whereas haloperidol induces a greater increase in the nucleus accumbens, the dorsolateral striatum and lateral septal nucleus. Collectively, our findings indicate that iptakalim is likely to be a potential antipsychotic drug with distinct

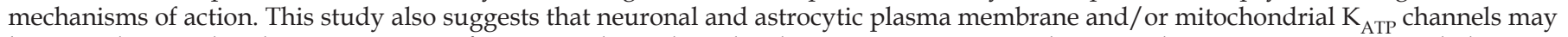
be a novel target that deserves attention for antipsychotic drug development. Future research using other sensitive tests is needed to confirm this property of iptakalim.
\end{abstract}

Keywords: Iptakalim, $\mathrm{K}_{\mathrm{ATP}}$ channel, Amphetamine, Phencyclidine, Antipsychotic drug, Conditioned avoidance response, Prepulse inhibition, c-Fos

\section{Introduction}

The traditional antipsychotic drug development process is essentially a trial-and-error approach (Carpenter and Koenig, 2008). New drugs were often developed as the result of duplicating the activity profile of the old antipsychotics, with slightly modified chemical structures (Valenstein, 1998). This drug discovery process has produced a series of drugs acting at the $\mathrm{D}_{2}$ receptor $/ 5-\mathrm{HT}_{2 \mathrm{~A}}$ receptors with similar efficacy as well as effectiveness against psychotic symptoms (Miyamoto et al., 2005), but has failed to produce novel antipsychotic drugs with novel molecular mechanisms. It appears that focusing solely on neuroreceptors as therapeutic targets may not be a fruitful approach in the identification and development of better antipsychotic drugs. A bold shift going beyond traditional neuroreceptors is urgently needed.

In light of this, iptakalim is particularly interesting. It is a novel adenosine triphosphate (ATP)-sensitive potassium $\left(\mathrm{K}_{\mathrm{ATP}}\right)$ channel opener that activates the cardiovascular $\mathrm{K}_{\mathrm{ATP}}$ channels and exerts a strong antihypertensive effect (Wang et al., 2005a; Wang et al., 2005b). Because iptakalim was later found to be able to easily pass through the blood-brain-barrier and act on the neuronal plasma membrane and/or mitochondrial $\mathrm{K}_{\mathrm{ATP}}$ channels, its potential therapeutic effects on neurological and neuropsychiatric disorders have generated much interest (Hu et al., 2006; Wang et al., 2006). Several lines of indirect evidence suggest that iptakalim may be potentially useful for schizophrenia and may offer needed benefits for negative and cognitive symptoms. First, in vivo experiments demonstrate that iptakalim has an inhibitory function on excess dopamine and glutamate release and can exert an intrinsic neuroprotective effect against necrosis, apoptosis and neurodegenerative disorders (Wang et al., 2004; Yang et al., 2006a; Yang et al., 2006b; Zhang et al., 2007; Zhou et al., 2007). Second, in animal behavioral studies, iptakalim does not cause catalepsy (unpublished observation) and is shown to reverse haloperidol-induced catalepsy and hypolocomotion (Wang et al., 2005c). Third, the target site of iptakalim - the $\mathrm{K}_{\mathrm{ATP}}$ channel - is found in the neural circuits that are implicated in the pathophysiology of schizophrenia, such as the substantia nigra, ventral tegmental area, the prefrontal cortex and hippocampus, and plays an important role in the regulation of release of neurotransmitters, such as glutamate, dopamine and GABA (Ross et al., 2006). Finally, it has been hypothesized that the $\mathrm{K}_{\mathrm{ATP}}$ channel activators may be beneficial for the treatment of schizophrenia (Allen and Etcheberrigaray, 1998; Freedman and Lin, 1996) based on the evidence that dopamine receptors can modulate the $\mathrm{K}_{\mathrm{ATP}}$ channel opening (Lin et al., 1993). Diazoxide, an ATP-sensitive potassium channel opener, has been tried in the clinic as an adjunctive treatment together with haloperidol. It potentiated the effects of haloperidol on the positive and general psychopathological symptoms of schizophrenia as measured by the Positive and Negative Syndrome Scale (PANSS) (Akhondzadeh et al., 2002). 
On the basis of the above evidence, we hypothesized that iptakalim is a novel drug with a therapeutic potential in schizophrenia. The primary aim of this study was to systematically validate its putative "antipsychotic" property using a variety of preclinical animal models. Iptakalim was compared to haloperidol, clozapine, and risperidone in tests predictive of antipsychotic activity. Specifically, we examined the effects of iptakalim treatment on (1) amphetamine-and phencyclidine -induced hyperlocomotor activity; (2) rat conditioned avoidance responding; (3) amphetamine- and phencyclidine-induced prepulse inhibition (PPI) deficits and (4) c-Fos expression in the prefrontal cortex, the dorsal striatum, the nucleus accumbens and lateral septum nucleus.

\section{Materials and methods}

\subsection{Animals}

Adult male Sprague-Dawley rats (226-250 g upon arrival, Charles River, Portage, MI) were used. They were housed two per cage, in $48.3 \mathrm{~cm} \times 26.7 \mathrm{~cm} \times 20.3 \mathrm{~cm}$ transparent polycarbonate cages under $12 \mathrm{~h}$ light/dark conditions (light on between 6:30 am and 6:30 pm). Room temperature was maintained at $22 \pm 1{ }^{\circ} \mathrm{C}$ with a relative humidity of $55-60 \%$. Food and water was available ad libitum. Animals were allowed at least one week of habituation to the animal facility before being used in experiments. All procedures were approved by the Institutional Animal Care and Use Committee at the University of Nebraska-Lincoln.

\subsection{Drugs}

The injection solution of haloperidol $(5.0 \mathrm{mg} / \mathrm{ml}$ ampoules, Sicor Pharmaceuticals, Inc, Irvine, CA) was obtained by mixing it with sterile water. The injection solutions of d-amphetamine sulfate (Sigma-RBI), phencyclidine hydrochloride (gift from NIDA Chemical Synthesis and Drug Supply Program), and fluoxetine (gift from the NIMH drug supply program) were obtained by mixing drugs with $0.9 \% \mathrm{NaCl}$ solution. Clozapine and risperidone (gifts from the NIMH drug supply program) were dissolved in $1.0-1.5 \%$ glacial acetic acid in distilled water. Iptakalim hydrochloride $(99.9 \%)$ was synthesized and provided by the Institute of Pharmacology and Toxicology, Academy of Military Medical Sciences of China as a gift to Dr. Hu. Iptakalim was dissolved in sterile water. Haloperidol, clozapine, risperidone, amphetamine and phencyclidine were administered subcutaneously, whereas fluoxetine and iptakalim was administered intraperitoneally in a volume of $1.0 \mathrm{ml} / \mathrm{kg}$ of body weight.

\subsection{Effects of iptakalim treatment on amphetamine-induced hy- perlocomotion and phencyclidine-induced hyperlocomotion}

Inhibition of locomotor hyperactivity induced by amphetamine or phencyclidine has been widely used as a screening tool for the "antipsychotic" property of a drug (Abekawa et al., 2007; Arnt, 1995; Millan et al., 1999; Millan et al., 2008). In this experiment, we examined the effects of acute iptakalim treatment on amphetamine-induced and phencyclidine-induced hyperlocomotion and compared its effect with that of risperidone and fluoxetine (a selective serotonin reuptake inhibitor with no known antipsychotic activity). After two days of habituation to the testing room and the testing boxes ( $30 \mathrm{~min} /$ day for 2 days), rats were first injected with the drug (i.e. risperidone 0.3 or $1.0 \mathrm{mg} / \mathrm{kg}$, fluoxetine 5.0 or $10.0 \mathrm{mg} / \mathrm{kg}$, or iptakalim 10, 30 and $60 \mathrm{mg} / \mathrm{kg}$ ) or vehicle on day 3 and placed in the locomotor activity boxes for a period of $30 \mathrm{~min}$ for habituation. Each transparent polycarbonate box $(48.3 \mathrm{~cm} \mathrm{~L} \times$ $26.7 \mathrm{~cm} \mathrm{~W} \times 20.3 \mathrm{~cm} \mathrm{H}$ ) was equipped with a row of 6 photocell beams $(7.8 \mathrm{~cm}$ between two adjacent photobeams) to record the number of photocell beam breaks. At the end of the 30-min pe- riod, rats were taken out and injected with amphetamine $(1.5 \mathrm{mg} /$ $\mathrm{kg}$, s.c.) or phencyclidine ( $3.2 \mathrm{mg} / \mathrm{kg}$, s.c.) and placed back in the boxes for another $60 \mathrm{~min}$. Locomotor activity (number of photobeam breaks) was measured throughout the entire 90 min testing session. The number of rats in each group was six to seven.

\subsection{Effects of iptakalim treatment on rat conditioned avoidance responding}

The conditioned avoidance response model is a well-established preclinical test for antipsychotic activity with high predictive validity (Arnt, 1982; Li et al., 2007; Wadenberg and Hicks, 1999). In this experiment, six custom-built two-compartment shuttle box systems (Med Associates, VT, USA) were used to train and test rats (see (Li et al., 2009a) and (Li et al., 2009b) for a detailed description of the apparatus). Sixty-six rats were first trained in a conditioned avoidance responding procedure for a total of eight sessions ( $\sim 2$ week period). Each training session consisted of 20 trials. During each trial, if a subject moved from one compartment into the other within the $10 \mathrm{~s}$ of conditioned stimulus $(76 \mathrm{~dB}$ white noise) presentation, the conditioned stimulus was terminated and the shock (unconditioned stimulus, US) was prevented, and this shuttling response was recorded as an avoidance. If the rat remained in the same compartment for more than $10 \mathrm{~s}$ and made a crossing upon receiving the footshock, this response was recorded as an escape. If the rat did not respond during the entire $5 \mathrm{~s}$ presentation of the shock, the trial was terminated and escape failure was recorded. At the end of the training session, 39 rats reached training criterion (> 14 avoidance trials in each of the last two sessions). They were then randomly assigned to one of six groups: vehicle (water, $n=7)$, haloperidol $(0.05 \mathrm{mg} / \mathrm{kg}$, s.c., $n=5)$, clozapine $(10 \mathrm{mg} / \mathrm{kg}$, s.c., $n=6)$, iptakalim $(10 \mathrm{mg} / \mathrm{kg}$, i.p., $n=7)$, iptakalim (30 mg/kg, i.p., $n=7)$ and iptakalim $(60 \mathrm{mg} / \mathrm{kg}$, i.p., $n=7)$. On the drug test day (1 day later), each rat was tested at 30 and 90 min after drug administration, and each test session included 20 trials.

\subsection{Effects of iptakalim treatment on amphetamine or phencycli- dine-induced prepulse inhibition deficits}

Reversal of amphetamine- and phencyclidine-induced PPI deficits has been used as a tool to identify chemical compounds with antipsychotic activity (Geyer et al., 2001). In this experiment, we examined the effects of acute iptakalim treatment on amphetamine- and phencyclidine-induced PPI deficit and compared its effect with those of clozapine and haloperidol. Six startle monitor systems (Kinder Scientific, Julian, CA) controlled by a PC were used. They were housed in compact sound attenuation cabinets ( $35.56 \mathrm{~cm}$ wide $\times 27.62 \mathrm{~cm}$ deep $\times 49.53 \mathrm{~cm}$ high). A speaker (diameter: $11 \mathrm{~cm}$ ) mounted on the cabinet's ceiling was used to generate acoustic stimuli (70 dB-120 dB). The startle activity was measured by a piezoelectric sensing platform on the floor. After two days of handling and habituation to the PPI apparatus, sixty rats were given a subcutaneous injection of saline and subjected to a brief "matching" session. Ten minutes after receiving an injection of saline, rats were placed individually into the PPI boxes and exposed to 5 min of $70 \mathrm{~dB}$ white background noise (which persisted through the entirety of the testing session) followed by 20 trials in pseudorandom order: 17 "PULSE ALONE" trials, each consisting of a 40 millisecond (ms) $120 \mathrm{~dB}$ noise burst, and 3 "PREPULSE + PULSE" trials consisting of a $20 \mathrm{~ms} 82 \mathrm{~dB}$ prepulse followed $100 \mathrm{~ms}$ later by a $120 \mathrm{~dB}$ pulse. Startle magnitude was defined as the maximum force (measured in Newtons) applied by the rat to the startle apparatus recorded over a period of $100 \mathrm{~ms}$ beginning at the onset of the pulse stimulus. The average startle response to the PULSE ALONE trials was used to create balanced treatment groups such that all groups had comparable base-line startle magnitudes. 
The amphetamine testing began one day after the matching session. Rats were weighed and injected with either water, clozapine $(10.0 \mathrm{mg} / \mathrm{kg})$, haloperidol $(0.05 \mathrm{mg} / \mathrm{kg})$, or one of three doses of iptakalim $(10,30$ or $60 \mathrm{mg} / \mathrm{kg}) 20 \mathrm{~min}$ prior to the injection of saline or amphetamine $(3.0 \mathrm{mg} / \mathrm{kg}$, s.c.), $10 \mathrm{~min}$ after which the rats were placed into the PPI boxes. Each testing session lasted approximately $18 \mathrm{~min}$ and began with a 5 min period of $70 \mathrm{~dB}$ background noise followed by four different trial types: PULSE ALONE trials, and three types of PREPULSE + PULSE trials, which consisted of a $20 \mathrm{~ms} 73,76$, or $82 \mathrm{~dB}$ prepulse $(3,6$, and $12 \mathrm{~dB}$ above background) followed $100 \mathrm{~ms}$ later by a $120 \mathrm{~dB}$ pulse (Culm and Hammer, 2004). Each session was divided into 4 blocks. Blocks 1 and 4 were identical, each consisting of 4 PULSE ALONE trials. Blocks 2 and 3 were also identical and each consisted of 8 PULSE ALONE trials and 5 of each PREPULSE + PULSE trial type. A total of 54 trials were presented during each testing session. Trials within each block were presented in a pseudorandom order and were separated by a variable intertrial interval averaging $15 \mathrm{~s}$ (ranging from 9 to $21 \mathrm{~s}$ ). Between each stimulus trial, $100 \mathrm{~ms}$ of activity was recorded when no stimulus was present. These trials were called NOSTIM trials and were not included in the calculation of intertrial intervals. Responses recorded during NOSTIM trials are considered a measure of motor activity within the PPI boxes. Responses to the first 4 trials and last 4 trials, which consisted of $120 \mathrm{~dB}$ pulse stimuli, were not included in the final PPI analysis. The percent of PPI expressed within each test session was calculated using the standard PPI equation: (100 - (mean Prepulse + Pulse response / mean Pulse response) / 100).

Following the amphetamine testing, rats were left alone for two days. One day later, they were re-assessed for PPI performance under no drug treatment condition to ensure that there was no PPI difference among the groups prior to the phencyclidine testing, which was conducted one day later. The same PPI testing procedure was used with the only exception that the rats who had previously received amphetamine $3.0 \mathrm{mg} / \mathrm{kg}$ now received phencyclidine $2.0 \mathrm{mg} / \mathrm{kg}$. The rest of the treatment and testing procedure remained unchanged. Phencyclidine at the chosen dose has been shown to induce a robust PPI deficit (Geyer et al., 2001).

\subsection{Effects of iptakalim treatment on c-Fos expression in rats}

The ability of antipsychotics to induce c-Fos protein in the forebrain regions has become a widely used molecular tool for identifying drugs with potential antipsychotic activity and liability for extrapyramidal side effects (EPS) (Mo et al., 2005; Natesan et al., 2006; Robertson and Fibiger, 1992; Robertson et al., 1994). This experiment compared the acute effect of iptakalim on c-Fos expression in the four forebrain regions with that of haloperidol and clozapine. Twenty-four rats were randomly assigned to 6 groups $(n=4$ / group) and injected with either saline (vehicle), haloperidol $0.5 \mathrm{mg}$ / $\mathrm{kg}$, clozapine $10.0 \mathrm{mg} / \mathrm{kg}$, iptakalim $10 \mathrm{mg} / \mathrm{kg}$, iptakalim $30 \mathrm{mg} /$ $\mathrm{kg}$ or iptakalim $60 \mathrm{mg} / \mathrm{kg}$. Two hours after drug administration, the rats were anesthetized with sodium pentobarbital $(100 \mathrm{mg} / \mathrm{kg}$ i. p.), and their brains were removed after transcardial perfusion with saline followed by $4 \%$ paraformaldehyde. The brains were postfixed in $4 \%$ paraformaldehyde, transferred to $30 \%$ sucrose solutions until settled down, and then stored at $-80^{\circ} \mathrm{C}$ until processing. The immunocytochemical procedure followed the protocol described in detail in our recent work (Zhao and Li, 2010). Fos immunoreactive nuclei, labeled with antiserum raised in rabbits against the Fos peptide 4-17 amino acids of human Fos (Oncogene Research Products, Cambridge, MA, USA), were counted within a $870 \times 650 \mu \mathrm{m}^{2}$ unit area unilaterally in three serial sections that were anatomically well-matched across the treatment groups. The brain regions analyzed included the medial prefrontal cortex, nucleus accumbens, dorsolateral striatum and lateral septal nucleus, corresponding to levels almost equal to Bregma $2.76 \mathrm{~mm}$ for medial prefrontal cortex and nucleus accumbens, $1.80 \mathrm{~mm}$ for dorsal striatum and lateral septum nucleus according to Paxinos and Watson (2007). The values from four rats of each treatment group were averaged to obtain the final mean \pm S.E.M.

In order to categorize iptakalim as a typical or atypical antipsychotic, we calculated the atypical index on the basis of the difference between the number of Fos-positive cells in the nucleus accumbens and dorsal striatum as described by Robertson et al. (1994). Briefly, the injection-corrected value in the nucleus accumbens and dorsal striatum was obtained by subtracting the number of Fos-positive nuclei in the vehicle-treated rats from that in the drug-treated ones. Atypical index was then yielded by subtracting the corrected number of Fos-positive cells in the dorsal striatum from that in the nucleus accumbens.

\subsection{Statistical analysis}

Data were expressed as mean values \pm S.E.M and analyzed using one-way ANOVA followed by Post-hoc LSD tests to identify twogroup differences. If data contained a within-subject factor (e.g. test days, prepulse intensities), then a factorial repeated measures ANOVA was used. A conventional two-tailed level of significance at the $5 \%$ level was required.

\section{Results}

\subsection{Effects of iptakalim treatment on amphetamine-induced hy- perlocomotion and phencyclidine-induced hyperlocomotion}

Figure $1 \mathrm{~A}$ shows the mean motor activity of the eight groups during the 60-min test period after amphetamine injection. Iptaka$\mathrm{lim}$ at $60 \mathrm{mg} / \mathrm{kg}$ and risperidone at both doses $(0.3$ and $1.0 \mathrm{mg} /$ $\mathrm{kg}$ ) significantly inhibited the hyperlocomotion induced by amphetamine, whereas fluoxetine potentiated this effect. One-way ANOVA revealed that there was a significant main effect of treatment $\left(F_{(7,47)}=19.665, P<0.001\right)$. Post-hoc tests showed that the
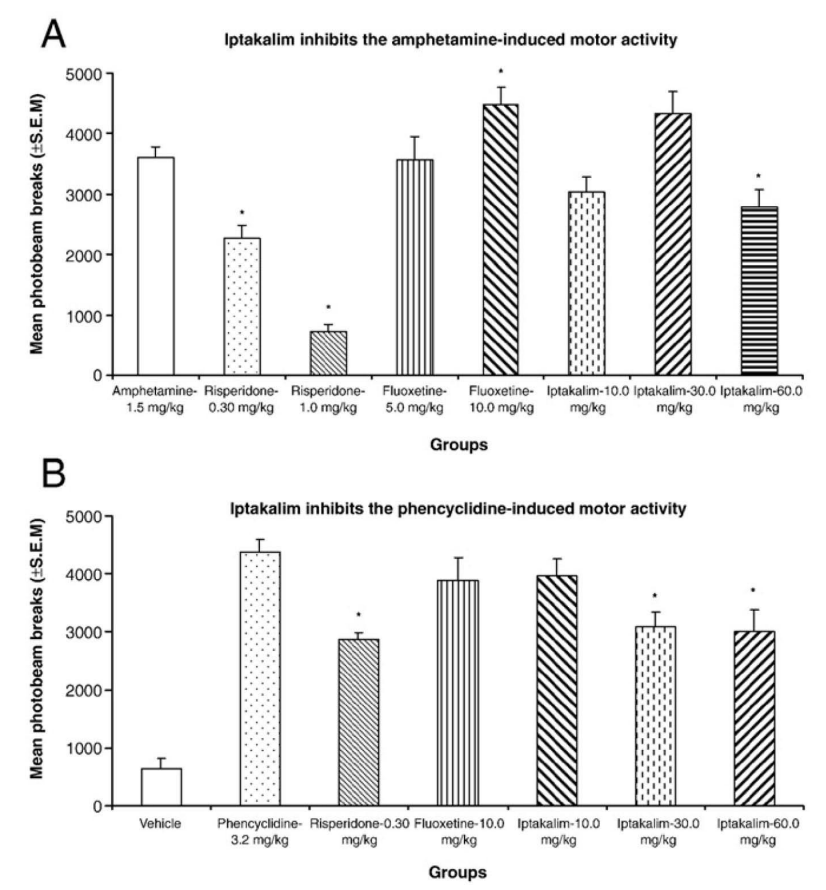

Figure 1. Effects of iptakalim, risperidone and fluoxetine pretreatment on amphetamine- and phencyclidine-induced hyperlocomotion. The drugs or vehicle was administered $30 \mathrm{~min}$ prior to amphetamine or phencyclidine challenge. Rats were tested for $60 \mathrm{~min}$ following amphetamine $(1.5 \mathrm{mg} / \mathrm{kg}$, s.c.) injection (A) or phencyclidine $(3.2 \mathrm{mg} /$ $\mathrm{kg}$, s.c.) injection (B). ${ }^{*} P<0.05$ in comparison to the vehicle + amphetamine or vehicle + phencyclidine group. 
amphetamine-induced hyperlocomotion effect was significantly attenuated by iptakalim at $60.0 \mathrm{mg} / \mathrm{kg}(P=0.038)$, risperidone at $0.3 \mathrm{mg} / \mathrm{kg}(P=0.001)$ and $1.0 \mathrm{mg} / \mathrm{kg}(P<0.001)$, whereas it was significantly enhanced by fluoxetine at $10 \mathrm{mg} / \mathrm{kg}(P=0.030)$ and marginally enhanced by iptakalim at $30 \mathrm{mg} / \mathrm{kg}(P=0.072)$. None of the other treatments (iptakalim at other doses) affected the amphetamine-induced hyperlocomotion.

Figure $1 \mathrm{~B}$ shows the mean motor activity of the seven groups of rats during the 60-min test period after vehicle or phencyclidine injection. Similar to their effects on amphetamine-induced hyperlocomotion, risperidone at $0.30 \mathrm{mg} / \mathrm{kg}$ and iptakalim at 30 and $60 \mathrm{mg} / \mathrm{kg}$ significantly inhibited phencyclidine-induced hyperlocomotion. One-way ANOVA revealed that there was a significant main effect of treatment $(F(6,47)=10.072, P<0.001)$. Post-hoc tests showed that in comparison to the vehicle treatment, phencyclidine produced a robust increase in motor activity $(P<0.001)$ which was significantly attenuated by iptakalim at 30 and $60 \mathrm{mg} / \mathrm{kg}$ and risperidone at $0.3 \mathrm{mg} / \mathrm{kg}(P=0.017,0.012$, and 0.006 respectively).

\subsection{Effects of iptakalim treatment on rat conditioned avoidance responding}

Figures $2 \mathrm{~A}$ and $\mathrm{B}$ show the mean avoidances at three time points (predrug day and drug day 1 at $30 \mathrm{~min}$ and $90 \mathrm{~min}$ ). At the $30 \mathrm{~min}$ point, iptakalim at $60 \mathrm{mg} / \mathrm{kg}$ significantly inhibited avoidance responding $(P=0.005)$, as did clozapine at $10 \mathrm{mg} / \mathrm{kg}(P<0.001)$ and haloperidol at $0.05 \mathrm{mg} / \mathrm{kg}(P=0.017)$. At the $90 \mathrm{~min}$ point, only clozapine still exerted a strong disruption of avoidance $(P=0.001)$.
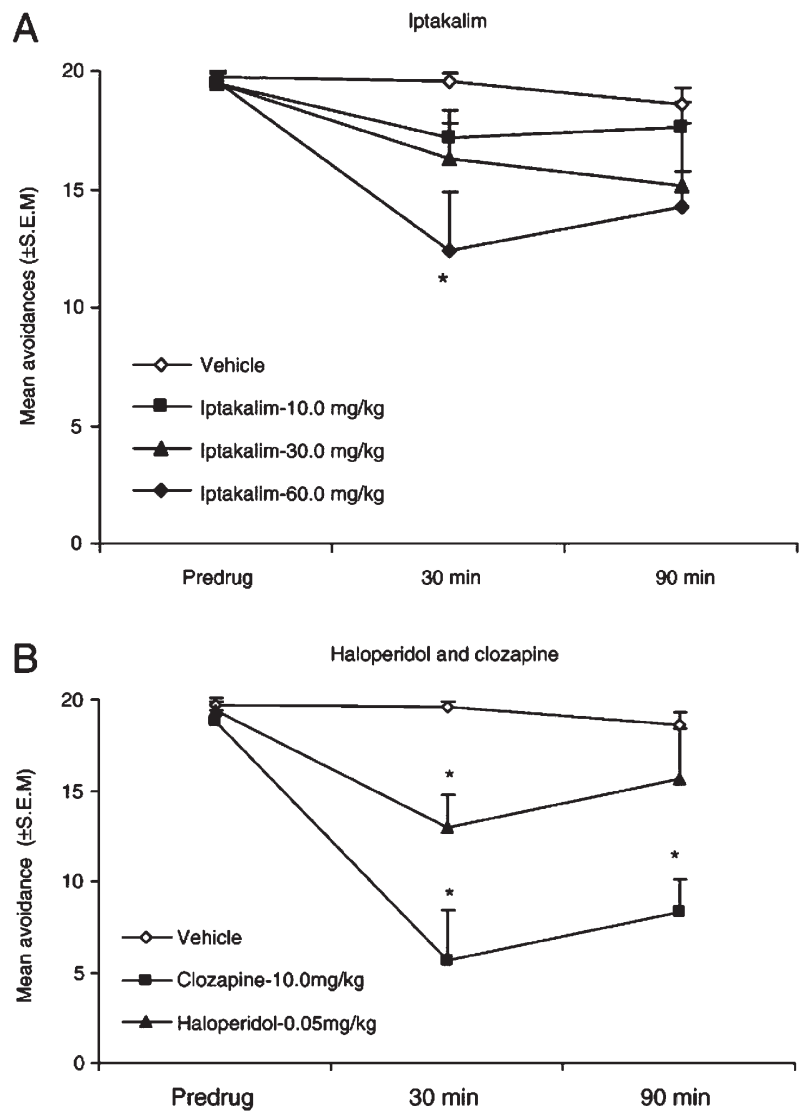

Figure 2. Effects of iptakalim (10, 30 and $60 \mathrm{mg} / \mathrm{kg}$, i.p.) (A), haloperidol $(0.05 \mathrm{mg} / \mathrm{kg}$, s.c.) and clozapine $(10.0 \mathrm{mg} / \mathrm{kg}$, s.c.) treatment (B) on conditioned avoidance response in rats tested at three time points (predrug day, $30 \mathrm{~min}$ and $90 \mathrm{~min}$ after drug administration). ${ }^{*} P<0.05$ in comparison to the vehicle group.
3.3. Effects of iptakalim treatment on amphetamine or phencyclidine-induced prepulse inhibition deficits

Figure 3A shows the mean percent PPI of the seven groups of rats during the amphetamine test. Acute amphetamine $(3.0 \mathrm{mg} / \mathrm{kg}$, s.c.) treatment did not produce a robust disruption of PPI. Strikingly, the combination of amphetamine and iptakalim produced a significant disruption on PPI. Repeated measures ANOVA revealed a significant effect of group $(F(6,53)=195.776, P<0.001)$ and prepulse level $(F(2,106)=99.155, P<0.001)$, but no significant group $\times$ level interaction $(F(12,106)=1.550, P=0.118)$. In comparison to the vehicle + vehicle condition, acute amphetamine slightly reduced \%PPI, especially at the $3 \mathrm{~dB}$ (above background) level, but this effect was not statistically significantly $(P=0.101)$. In contrast, all three iptakalim groups $\left(P_{\mathrm{S}}<0.001\right)$ and the haloperidol group $(P=0.019)$ showed significant lower \%PPI than the vehicle + vehicle group. The combined disruptive effect of iptakalim and amphetamine was also indicated by the finding that all three iptakalim groups differed significantly from the vehicle + amphetamine group $(P=0.010$ for iptakalim $10 \mathrm{mg} / \mathrm{kg}$ and $P \mathrm{~s}<0.001$ for

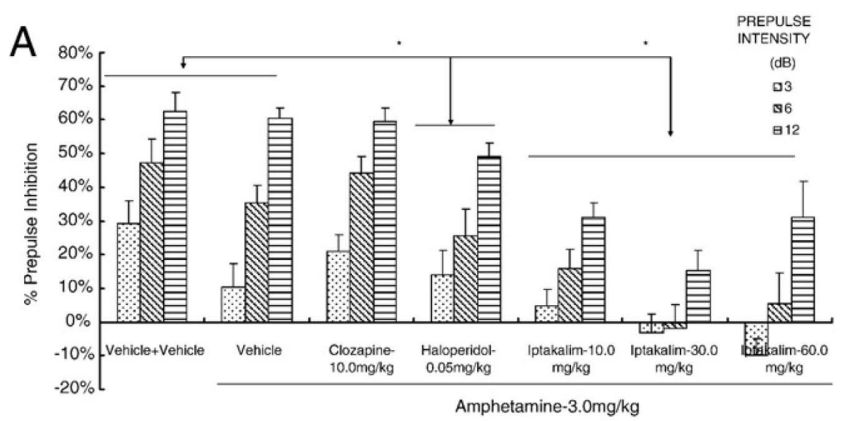

B

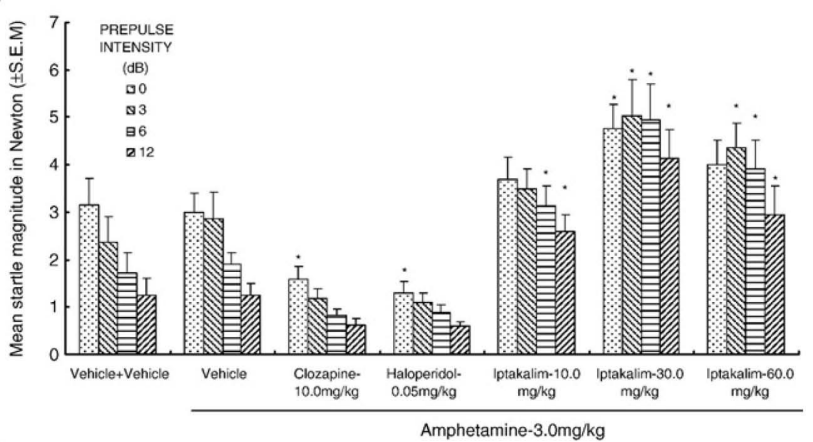

C

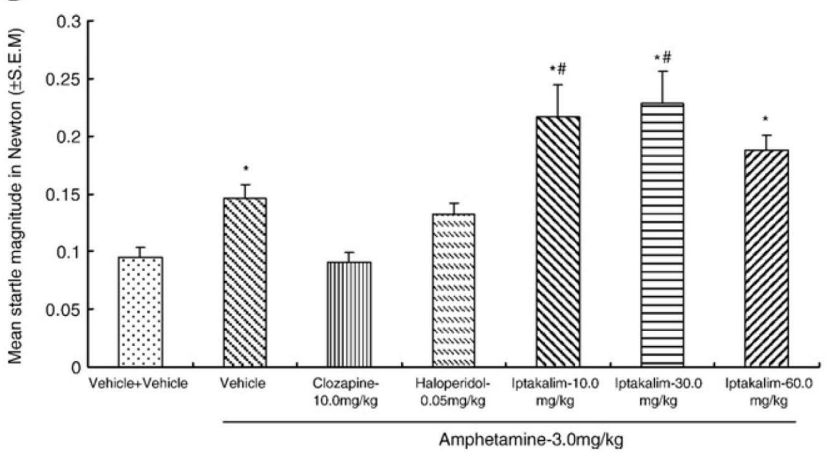

Figure 3. Effects of iptakalim (10, 30 and $60 \mathrm{mg} / \mathrm{kg}$, i.p.), haloperidol $(0.05 \mathrm{mg} / \mathrm{kg}$, s.c.) and clozapine $(10.0 \mathrm{mg} / \mathrm{kg}$, s.c.) treatment on amphetamine $(3.0 \mathrm{mg} / \mathrm{kg}$, s.c.)-induced PPI reduction (A) and startle reactivity in prepulse and pulse trials (B) and NOSTIM trials (C). Haloperidol, clozapine, iptakalim or vehicle was injected $20 \mathrm{~min}$ prior to the injection of saline or amphetamine, $10 \mathrm{~min}$ after which, the rats were tested. ${ }^{*} P<0.05$ in comparison to the vehicle + vehicle group; $\# P<0.05$ in comparison to the vehicle + amphetamine group. 

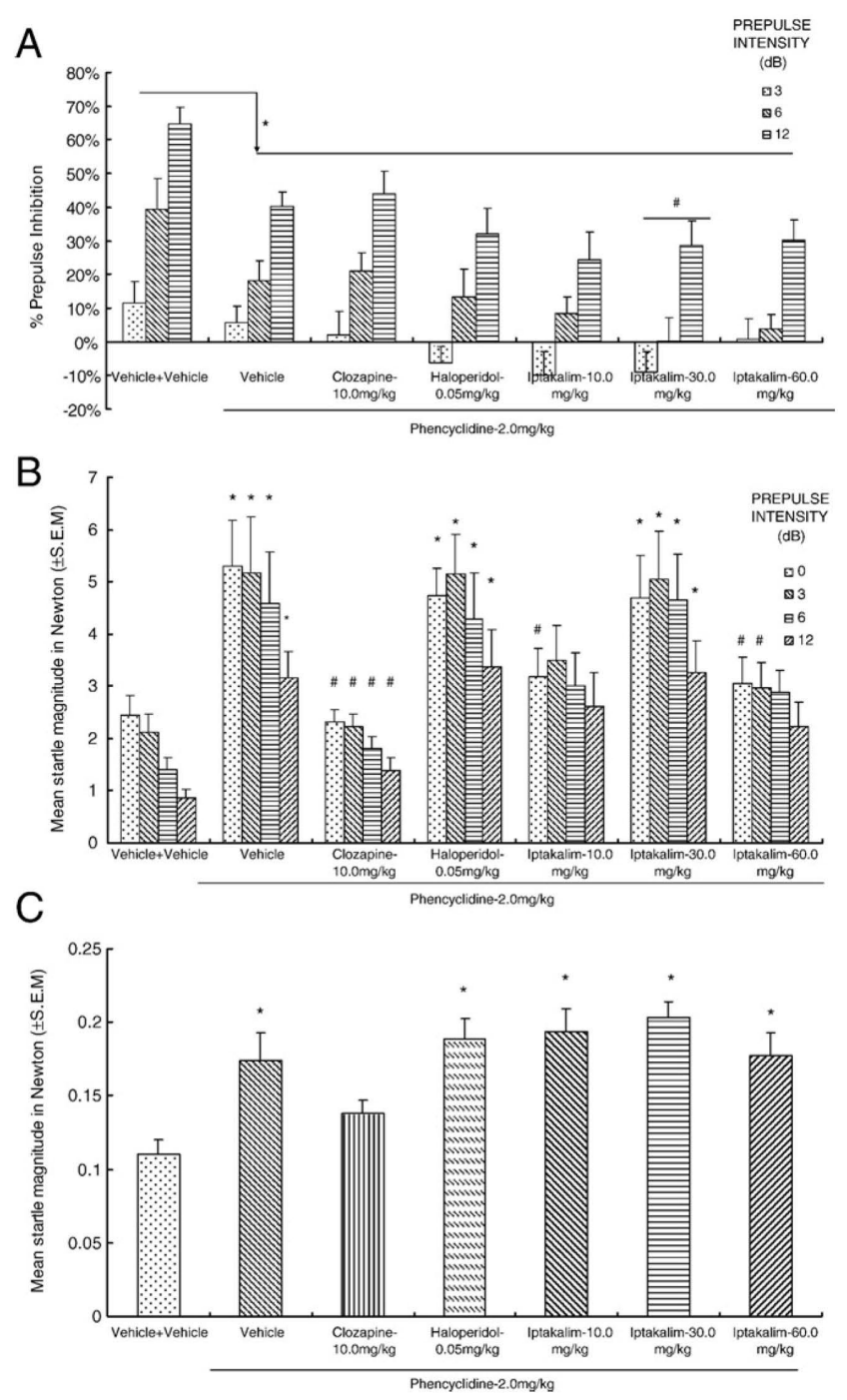

Figure 4. Effects of iptakalim (10, 30 and $60 \mathrm{mg} / \mathrm{kg}$, i.p.), haloperidol $(0.05 \mathrm{mg} / \mathrm{kg}$, s.c.) and clozapine $(10.0 \mathrm{mg} / \mathrm{kg}$, s.c.) treatment on phencyclidine $(2.0 \mathrm{mg} / \mathrm{kg}$, s.c.)-induced PPI deficit (A) and startle reactivity in prepulse and pulse trials (B) and NOSTIM trials (C). Haloperidol, clozapine, iptakalim or vehicle was injected $20 \mathrm{~min}$ prior to the injection of saline or phencyclidine, $10 \mathrm{~min}$ after which, the rats were tested. ${ }^{*} P<0.05$ in comparison to the vehicle + vehicle group; $\# P<0.05$ in comparison to the vehicle + phencyclidine group.

the other two iptakalim groups). Clozapine pretreatment had little impact on PPI as there was no group difference between the clozapine group and the vehicle + vehicle group $(P=0.481)$ nor the vehicle + amphetamine group $(P=0.351)$.

To examine the possible causes of the disruptive effect of combined iptakalim + amphetamine on PPI, we examined the mean magnitude of acoustic startle responses (ASR) in the three prepulse $(3,6,12 \mathrm{~dB})$ and pulse alone $(120 \mathrm{~dB})$ trials. As can be seen in Figure $3 \mathrm{~B}$, iptakalim pretreatment preferentially enhanced the ASR magnitude in the prepulse trials over that in the pulse alone trials. One-way ANOVAs showed that the ASR magnitude in the three prepulse trials was significantly higher in the iptakalim groups than the vehicle + vehicle and vehicle + amphetamine groups (all $P$ s $<0.05$ with the only exception of the iptakalim $10 \mathrm{mg} / \mathrm{kg}$ group at the $3 \mathrm{~dB}$ level, $P=0.115)$. For the ASR in the pulse alone trials, only the iptakalim $30 \mathrm{mg} / \mathrm{kg}$ group differed from the two vehicle groups $\left(P_{\mathrm{s}}<0.013\right)$. Thus the lowered PPI in the iptakalim + am- phetamine groups could be attributed to the preferentially increased ASR magnitude in the prepulse trials over the pulse alone trials, an indication of PPI deficit (Swerdlow et al., 2001).

We also examined the startle magnitude in the NOSTIM trials (no pulse) (Figure 3C). Responses recorded during NOSTIM trials are considered a measure of gross motor activity within the PPI boxes. Acute amphetamine enhanced the startle magnitude measured under this condition ( $P=0.027$ vs. vehicle). Iptakalim pretreatment with amphetamine further potentiated this effect. In comparison to the vehicle + vehicle group, all three iptakalim + amphetamine groups showed significantly higher startle magnitude $\left(P_{S}<0.001\right)$, which was further enhanced by iptakalim at 10 and $30 \mathrm{mg} / \mathrm{kg}\left(P_{\mathrm{s}}<0.005\right)$, and marginally enhanced by iptakalim at $60 \mathrm{mg} / \mathrm{kg}(P=0.083)$.

On the pre-phencyclidine testing day ( 3 days after the amphetamine test), all groups showed comparable levels of PPI as no significant group difference was detected $(F(6,53)=0.680$, $P=0.667$, data not shown). On the phencyclidine test day, all the phencyclidine-treated groups showed significantly lower $\%$ PPI at all three levels (see Figure 4A). There was a main effect of group $(F(6,53)=4.944, P<0.001)$ and prepulse level $(F(2,106)=109.90, P<0.001)$, but no significant group $\times$ level interaction $(F(12,106)=0.983, P=0.470)$. Post-hoc comparisons revealed that acute phencyclidine $2.0 \mathrm{mg} / \mathrm{kg}$ significantly disrupted PPI (all Ps < 0.026). Pretreatment of haloperidol, clozapine and iptakalim did not reverse the phencyclidine-induced PPI deficits (all Ps $>0.05)$. In contrast, the iptakalim $30 \mathrm{mg} / \mathrm{kg}+$ phencyclidine group showed even lower $\%$ PPI than the vehicle + phencyclidine group $(P=0.039)$.

Figure $4 \mathrm{~B}$ shows the mean magnitude of acoustic startle responses (ASR) in the three prepulse $(3,6,12 \mathrm{~dB})$ and pulse alone $(120 \mathrm{~dB})$ trials in the phencyclidine test. Acute phencyclidine treatment significantly increased the ASR magnitude at all $4 \mathrm{lev}$ els (Post-hoc comparison, vehicle + vehicle vs. vehicle + phencyclidine, $P=0.001)$, an effect that was completely reversed by pretreatment of clozapine $(P=0.003)$ and iptakalim at $60 \mathrm{mg} /$ $\mathrm{kg}(P=0.043)$, and to a lesser extent by iptakalim at $10 \mathrm{mg} / \mathrm{kg}$ $(P=0.087)$. Pretreatment of haloperidol or iptakalim at $30 \mathrm{mg} / \mathrm{kg}$ had little effect on the ASR enhancing effect of phencyclidine (all $P$ s $>0.05$ in comparison to the vehicle + phencyclidine group).

On the startle magnitude in the NOSTIM trials (no pulse), acute phencyclidine treatment significantly enhanced this measure $(P=0.001$ between the vehicle + vehicle and vehicle + phencyclidine groups, Figure $4 \mathrm{C}$ ). This effect of phencyclidine was reversed only by clozapine pretreatment $(P=0.145$ between the vehicle + vehicle and clozapine + phencyclidine group), but not by any other pretreatments.

\subsection{Effects of iptakalim treatment on c-Fos expression in rats}

Figure 5 shows the schematic representation of the forebrain regions (rectangles) in which the c-Fos immunoreactive neurons were counted. As can be seen in Figure 6A and B, iptakalim at 30.0 and $60.0 \mathrm{mg} / \mathrm{kg}$, as well as haloperidol and clozapine produced significant increases in the number of Fos-positive neurons in the nucleus accumbens and lateral septum nucleus (all $P_{S}<0.05$ ), whereas $10.0 \mathrm{mg} / \mathrm{kg}$ of iptakalim had no effect on c-Fos expression. In addition, haloperidol significantly increased Fos-positive neurons in the dorsal striatum $(P<0.001)$, whereas iptakalim and clozapine were without effect $(P>0.10)$. This similarity between iptakalim and clozapine was further confirmed by the atypical index (Robertson et al., 1994). As shown in Figure 6C, both iptakalim and clozapine, but not haloperidol, exhibited a positive atypical antipsychotic profile. Among the four brain areas that were examined, iptakalim produced effects similar to clozapine, but dissimilar to haloperidol, and substantially increased c-Fos expression in the medial prefrontal cortex in comparison to other sites. 


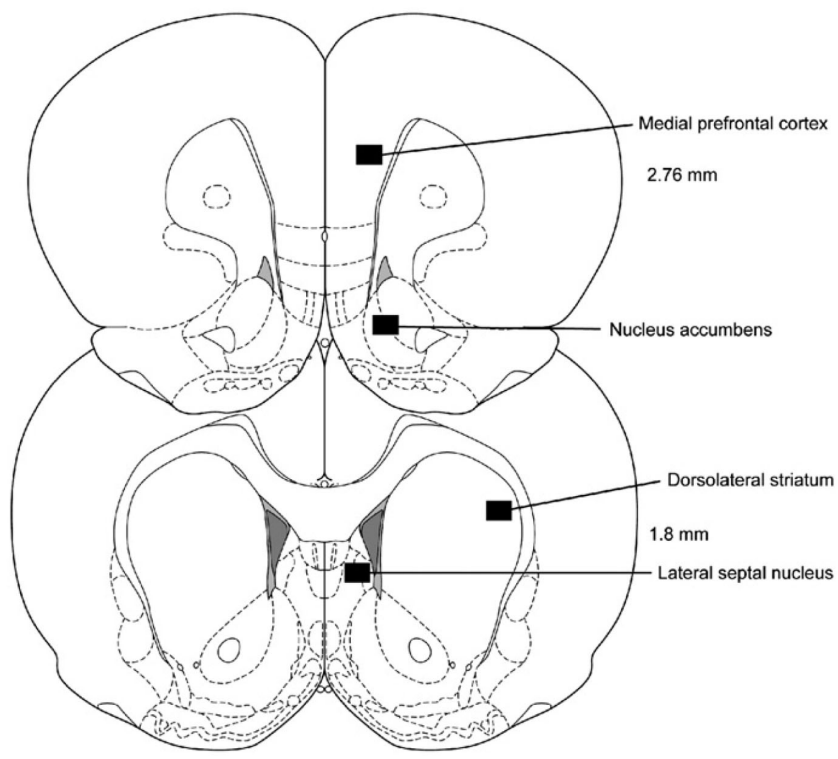

Figure 5. Schematic representation of the forebrain regions (rectangles) in which the c-Fos immunoreactive neurons were counted. Distance from bregma in the rostrocaudal planes is indicated. Drawings were modified from Paxinos and Watson (2007) with permission.

\section{Discussion}

This work was our first attempt to investigate the potential antipsychotic activity of iptakalim. Using well-established animal models predictive of antipsychotic activity, we showed that iptakalim may possess a potential antipsychotic efficacy with some unique effects. Specifically, we found that iptakalim is effective in reducing both amphetamine- and phencyclidine-induced locomotor activity, and suppressing avoidance responding, a behavioral profile shared with all currently used antipsychotics (Abekawa et al., 2007; Arnt, 1995; Millan et al., 1999; Millan et al., 2008; Sun et al., 2009; Wadenberg and Hicks, 1999). Neuroanatomically, iptakalim also exhibits an antipsychotic profile. It dose-dependently increased c-Fos expression in the nucleus accumbens, medial prefrontal cortex and lateral septal nucleus, but not in the dorsolateral striatum. All these findings are consistent with the behavioral and molecular profiles of antipsychotics. On the other hand, we also found that the combined iptakalim and amphetamine treatment produces a disruption of PPI. This finding seems inconsistent with the known antipsychotic profile. However, the combination of haloperidol and amphetamine also shows this effect, which suggests that this seemingly negative finding may not be sufficient to refute the potential antipsychotic activity of iptakalim.

In the present study, we found several similarities between iptakalim and clozapine. Both drugs showed an ability to attenuate phencyclidine-induced increase of startle reactivity in the PPI test (Figure 4B). They also disrupted avoidance responding and exhibited a preferential action on c-Fos expression in the medial prefrontal cortex, nucleus accumbens and lateral septum nucleus over in the dorsal striatum. One notable difference between iptakalim and clozapine was their effects on the amphetamine-induced PPI reduction. Iptakalim in combination with amphetamine caused PPI deficits, whereas clozapine in combination with amphetamine did not. Haloperidol at the tested dose $(0.05 \mathrm{mg} / \mathrm{kg})$ in combination with amphetamine also caused PPI deficits. The potentiated effect of iptakalim and haloperidol was an unexpected finding, contrary to our expectation. It is puzzling given the fact that iptakalim showed an inhibitory effect on amphetamine-induced hyperlocomotion and did not disrupt PPI when given alone (unpublished observation). In the literature, the effectiveness of antipsychotics in countering effects of indirect DA agonists such as amphetamine has not been examined thoroughly (Geyer et al., 2001). There are only a handful of reports showing that haloperidol blocks the effects of amphetamine on PPI (Andersen and Pouzet, 2001; Feifel et al., 1999). Thus, reversal of amphetamine-induced PPI deficit may not be a universal and well-established criterion for antipsychotic activity. Most PPI studies focus on the effect of antipsychotics on the direct DA agonist apomorphine because PPI is more sensitive to the effects of apomorphine than to the effects of amphetamine. Thus future work should examine how iptakalim treatment affects apomorphine-induced disruption of PPI. Such work is currently being undertaken in our laboratory.

Similarly, we also did not observe any reversal effect of iptakalim, clozapine or haloperidol pretreatment on phencyclidine-induced PPI deficits. It has been commonly reported in the literature that typical antipsychotics such as haloperidol are ineffective in reducing the effects of phencyclidine and other NMDA antagonists on PPI in rats (see a comprehensive review (Geyer et al., 2001)). Studies on atypical antipsychotics have not yielded consistent results (Swerdlow et al., 1996). As noted by Geyer et al (2001), "clozapine, being the most tested atypical antipsychotic in the glutamatergic PPI model, has the largest number of inconsistencies" probably due to its complex receptor mechanisms of action. Therefore, in the hindsight, the amphetamine and phencyclidine PPI models may not be the best choices to test antipsychotic activity of iptakalim, as they may have limited predictive value for antipsychotic activity and pose a challenge for data interpretation. One possible reason is that they may reflect cognitive deficits of schizophrenia (as opposed to psychosis) (Swerdlow et al., 2008), which are less responsive to antipsychotic treatment.

Typical antipsychotics usually produce a large increase in cFos expression in the dorsal striatum than in the nucleus accumbens, whereas atypical antipsychotics preferentially increase the c-Fos expression in the nucleus accumbens, having either little or no effect in the dorsal striatum. Our c-Fos immunocytochemistry study provided another line of evidence in support of the atypical antipsychotic property of iptakalim. This property is further supported by its exhibited atypical index (Robertson and Fibiger, 1992; Robertson et al., 1994). One remarkable effect of iptakalim was its strong action in the medial prefrontal cortex. In fact, among the four brain regions examined, iptakalim increased c-Fos expression more in the medial prefrontal cortex than in any other regions. The medial prefrontal cortex plays a critical role in various psychological functions, such as attention, memory, executive functioning and emotional regulations, all of which are found to be impaired to some extent in patients with schizophrenia (Belujon and Grace, 2008; Moghaddam and Homayoun, 2008). Since clozapine's actions on negative symptoms are thought to be associated with its action in this region, the strong action of iptakalim in this region indicates that iptakalim may be particularly efficacious against negative symptoms and cognitive deficits in schizophrenia by improving the function of the medial prefrontal cortex.

The putative target sites of iptakalim - the $\mathrm{K}_{\mathrm{ATP}}$ channels - are the heteroctameric complexes, consisting of discrete pore-forming (inwardly rectifying potassium subunit; Kir6.1/Kir6.2) and regulatory subunits (sulfonylurea receptors; SUR1/SUR2). The channels are usually closed in normal conditions but are activated rapidly in response to a decrease in intracellular ATP/ADP ratio under metabolic stress or stoke or by selective channel openers. Opening of $\mathrm{K}_{\mathrm{ATP}}$ channels results in hyperpolarization of the cell membrane and limitation of $\mathrm{Ca}^{2+}$ influx, thus blocking subsequent neurotoxic biochemical cascades (Miki and Seino, 2005) and reducing neurotransmitter release. Because the $\mathrm{K}_{\mathrm{ATP}}$ channels are widely distributed throughout the mammalian brain (Dunn-Meynell et al., 1998; Thomzig et al., 2005) and are found in the neural circuits that are implicated in the pathophysiology of schizophrenia, iptakalim might broadly impact brain functions by opening these 
A

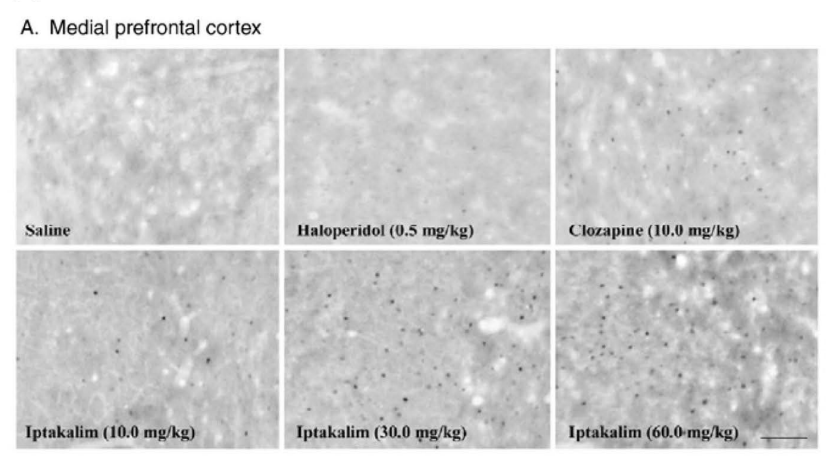

C. Dorsolateral striatum

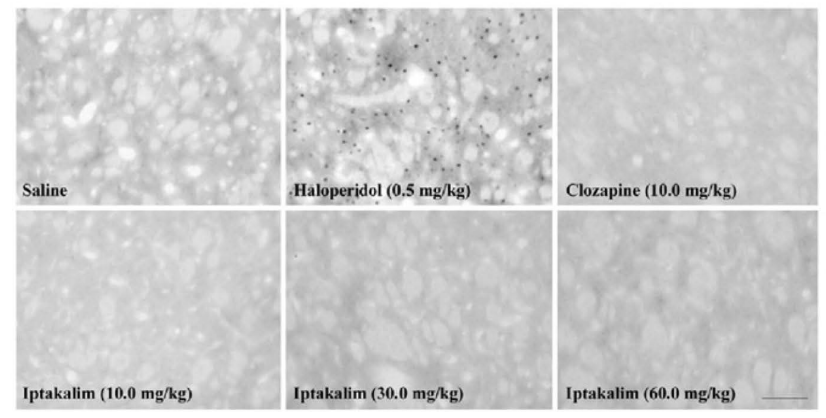

$\mathrm{B}$

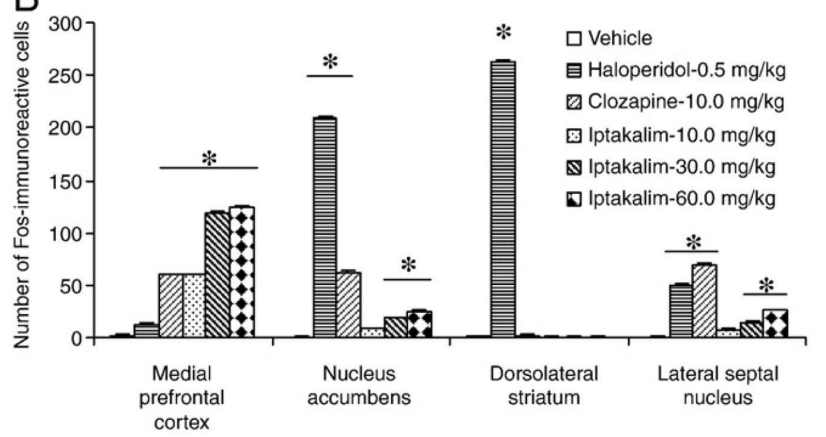

B. Nucleus accumbens

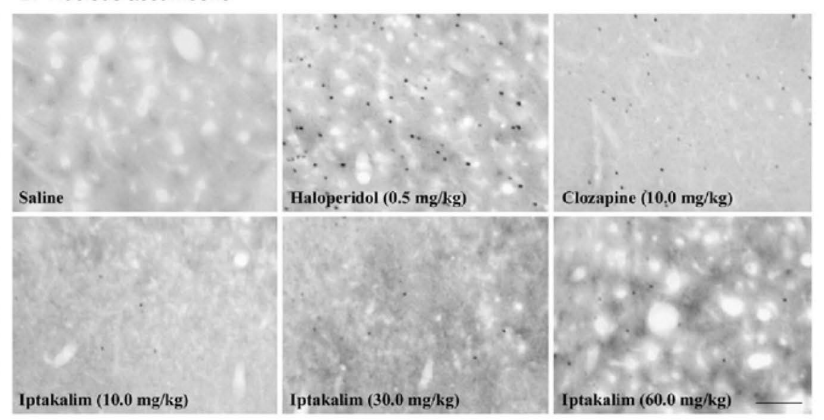

D. Lateral septal nucleus

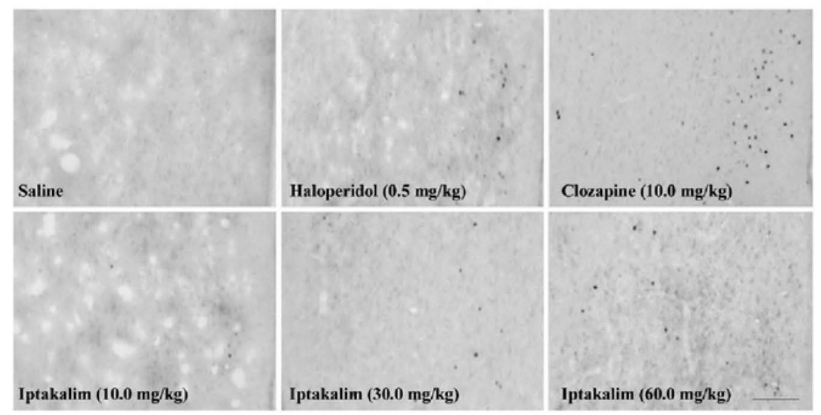

C

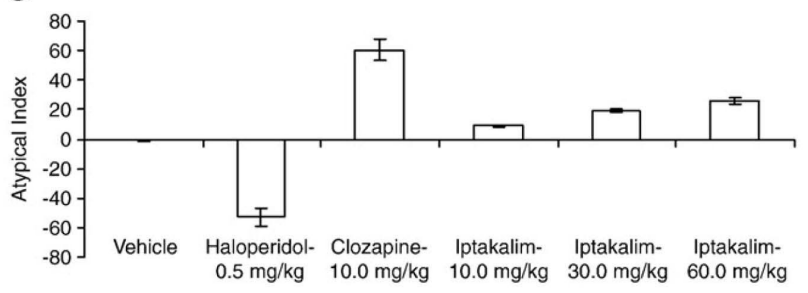

Figure 6. (A) Representative images of effects of acute treatment with iptakalim (10, 30 and $60 \mathrm{mg} / \mathrm{kg}$, i.p.), haloperidol (0.5 mg/ kg, s.c.) and clozapine $(10.0 \mathrm{mg} / \mathrm{kg}$, s.c.) on Fos expression in the four brain regions (e.g. medial prefrontal cortex, nucleus accumbens, dorsolateral striatum and lateral septal nucleus) in rats. Rats were sacrificed $2 \mathrm{~h}$ after vehicle or drug administration. (B) Quantification of effects of acute iptakalim, haloperidol or clozapine treatment on the mean number of Fos-positive neurons within a $870 \times 650 \mu \mathrm{m}^{2}$ area in the medial prefrontal cortex, nucleus accumbens, dorsolateral striatum and lateral septal nucleus (B). Each bar represents the mean + S.E.M of data from four rats. ${ }^{*} P<0.05$ in comparison to the vehicle group. (C) Atypical index based on number of Fos-positive neurons in the dorsolateral striatum and nucleus accumbens.

$\mathrm{K}_{\text {ATP }}$ channels and modulating glutamate and dopamine releases when the brain is under stress (in a sense, a dysfunctional schizophrenic brain can be considered as under certain unknown stress) (Yang et al., 2008). We thus propose that amphetamine, phencyclidine or a conditioned stimulus (as in the avoidance task) increases dopamine and glutamate release in the nucleus accumbens and medial prefrontal cortex by activating dopaminergic neurons in the ventral tegmental area (VTA) (Abekawa et al., 2007; Bowyer et al., 1984; Hertel et al., 1995; Swanson and Schoepp, 2003; Zweifel et al., 2009). Iptakalim, by opening $\mathrm{K}_{\mathrm{ATP}}$ channels located on the VTA dopamine neurons, inhibits dopamine and glutamate release (Wang et al., 2006; Yang et al., 2006b) and attenuates the behavioral and c-Fos expression effects induced by amphetamine, phencyclidine or conditioned stimulus.

The importance of potassium channels in schizophrenia as a valid target for future antipsychotic drugs is supported by a recent demonstration that retigabine, a selective KCNQ channel opener, exhibits an antipsychotic-like property in various preclinical an- imal models (e.g., dopaminergic cell firing, amphetamine- and phencyclidine-induced hyperlocomotion and conditioned avoidance response) (Sotty et al., 2008). KCNQ channels (also named Kv7) are voltage-dependent potassium channels that are found in the mesolimbic dopamine neurons. They share with $\mathrm{K}_{\mathrm{ATP}}$ channels the property of inhibiting neuronal excitation. Another interesting piece of evidence is that estrogen, which regulates the activity of potassium large conductance calcium-activated channels known as BK channels (Dick and Sanders, 2001), has an antipsychotic-like effect (Kulkarni et al., 2001).

We should point out several limitations with the present study. First, we used a limited number of behavioral models and c-Fos immunocytochemistry to identify the antipsychotic property of iptakalim. The exact molecular mechanisms responsible for iptakalim effects in these tests have not been addressed. Second, we have not compared iptakalim with other ATP-sensitive potassium openers such as diazoxide in animal models of antipsychotic drugs, thus whether the $\mathrm{K}_{\mathrm{ATP}}$ channels represent an effective 
novel target for future antipsychotics remain to be determined. Third, we did not examine to what extent iptakalim's peripheral antihypertensive effect contributes to its behavioral effects as shown in this study, and we also have not examined the chronic effect of iptakalim treatment on other animal models of antipsychotic drugs. Nevertheless, the present study provides important preliminary evidence suggesting that iptakalim may function as a novel antipsychotic drug. If iptakalim's therapeutic potentials are confirmed, it would contribute to broader understanding of the neuropathophysiology of schizophrenia and intensify the effort to further examine the role of the $\mathrm{K}_{\mathrm{ATP}}$ channel in the etiology of schizophrenia.

\section{Acknowledgments}

This study was funded by a research grant (07R-1775) from the Stanley Medical Research Institute to Professors Ming Li (Principal Investigator) and Gang $\mathrm{Hu}$ (Co-Investigator). The funding sources have no involvement in the study design; in the collection, analysis and interpretation of data; in the writing of the report; and in the decision to submit the paper for publication. We thank Professor Ronald Hammer Jr. at the University of Arizona College of Medicine for his technical support of PPI test. We thank Mr. Wei He for excellent technical assistance and Natashia Swalve for editorial help. We thank the two anonymous reviewers for European Journal of Pharmacology for their insightful comments.

\section{References}

Abekawa et al., 2007 T. Abekawa, K. Ito and T. Koyama, Different effects of a single and repeated administration of clozapine on phencyclidine-induced hyperlocomotion and glutamate releases in the rat medial prefrontal cortex at short- and long-term withdrawal from this antipsychotic, Naunyn Schmiedebergs Arch. Pharmacol. 375 (2007), pp. 261-271.

Akhondzadeh et al., 2002 S. Akhondzadeh, V. Mojtahedzadeh, G. R. Mirsepassi, M. Moin, H. Amini-Nooshabadi and A. Kamalipour, Diazoxide in the treatment of schizophrenia: novel application of potassium channel openers in the treatment of schizophrenia, J. Clin. Pharm. Ther. 27 (2002), pp. 453-459.

Allen and Etcheberrigaray, $1998>$ J. W. Allen and R. Etcheberrigaray, Potassium channels in neuropsychiatric disorders: potential for pharmacological intervention, CNS Drugs 10 (1998), pp. 61-82.

Andersen and Pouzet, $2001>$ M. P. Andersen and B. Pouzet, Effects of acute versus chronic treatment with typical or atypical antipsychotics on d-amphetamine-induced sensorimotor gating deficits in rats, Psychopharmacology (Berl) 156 (2001), pp. 291-304.

Arnt, 1982 J. Arnt, Pharmacological specificity of conditioned avoidance response inhibition in rats: inhibition by neuroleptics and correlation to dopamine receptor blockade, Acta Pharmacol. Toxicol. (Copenh) 51 (1982), pp. 321-329.

Arnt, 1995 J. Arnt, Differential effects of classical and newer antipsychotics on the hypermotility induced by two dose levels of damphetamine, Eur. J. Pharmacol. 283 (1995), pp. 55-62.

Belujon and Grace, $2008 \longrightarrow$ P. Belujon and A. A. Grace, Critical role of the prefrontal cortex in the regulation of hippocampus-accumbens information flow, J. Neurosci. 28 (2008), pp. 9797-9805.

Bowyer et al., 1984 J. F. Bowyer, K. P. Spuhler and N. Weiner, Effects of phencyclidine, amphetamine and related compounds on dopamine release from and uptake into striatal synaptosomes, J. Pharmacol. Exp. Ther. 229 (1984), pp. 671-680.

Carpenter and Koenig, 2008 W. T. Carpenter and J. I. Koenig, The evolution of drug development in schizophrenia: past issues and future opportunities, Neuropsychopharmacology 33 (2008), pp. 2061-2079.

Culm and Hammer, 2004 K. E. Culm and R. P. Hammer Jr., Recovery of sensorimotor gating without $\mathrm{G}$ protein adaptation after repeated D2-like dopamine receptor agonist treatment in rats, J. Pharmacol. Exp. Ther. 308 (2004), pp. 487-494.

Dick and Sanders, 2001 G. M. Dick and K. M. Sanders, (Xeno)estrogen sensitivity of smooth muscle BK channels con- ferred by the regulatory beta1 subunit: a study of beta1 knockout mice, J. Biol. Chem. 276 (2001), pp. 44835-44840.

Dunn-Meynell et al., 1998 A. A. Dunn-Meynell, N. E. Rawson and B. E. Levin, Distribution and phenotype of neurons containing the ATP-sensitive K+ channel in rat brain, Brain Res. 814 (1998), pp. $41-54$.

Feifel et al., 1999 D. Feifel, T. Reza and S. Robeck, Antipsychotic potential of CCK-based treatments: an assessment using the prepulse inhibition model of psychosis, Neuropsychopharmacology 20 (1999), pp. 141-149.

Freedman and Lin, 1996 J. E. Freedman and Y. J. Lin, ATP-sensitive potassium channels: diverse functions in the central nervous system, Neuroscientist 2 (1996), pp. 145-152.

Geyer et al., 2001 M. A. Geyer, K. Krebs-Thomson, D. L. Braff and N. R. Swerdlow, Pharmacological studies of prepulse inhibition models of sensorimotor gating deficits in schizophrenia: a decade in review, Psychopharmacology (Berl) 156 (2001), pp. 117-154.

Hertel et al., 1995 P P. Hertel, J. M. Mathe, G. G. Nomikos, M. Iurlo, A. A. Mathe and T. H. Svensson, Effects of d-amphetamine and phencyclidine on behavior and extracellular concentrations of neurotensin and dopamine in the ventral striatum and the medial prefrontal cortex of the rat, Behav. Brain Res. 72 (1995), pp. 103-114.

Hu et al., 2006 J. Hu, K. Lindenberger, G. Hu, H. Wang, R. J. Lukas and $\mathrm{J}$. Wu, Iptakalim as a human nicotinic acetylcholine receptor antagonist, J. Pharmacol. Exp. Ther. 316 (2006), pp. 914-925.

Kulkarni et al., 2001 J. Kulkarni, A. Riedel, A. R. de Castella, P. B. Fitzgerald, T. J. Rolfe, J. Taffe and H. Burger, Estrogen - a potential treatment for schizophrenia, Schizophr. Res. 48 (2001), pp. 137-144.

Li et al., $2007 \rightarrow \mathrm{M}$. Li, P. J. Fletcher and S. Kapur, Time course of the antipsychotic effect and the underlying behavioral mechanisms, Neuropsychopharmacology 32 (2007), pp. 263-272.

Li et al., 2009a M. Li, W. He and A. Mead, An investigation of the behavioral mechanisms of antipsychotic action using a drug-drug conditioning paradigm, Behav. Pharmacol. 20 (2009), pp. 184-194.

Li et al., 2009b M. Li, W. He and A. Mead, Olanzapine and risperidone disrupt conditioned avoidance responding in phencyclidine-pretreated or amphetamine-pretreated rats by selectively weakening motivational salience of conditioned stimulus, Behav. Pharmacol. 20 (2009), pp. 84-98.

Lin et al., 1993 Y. J. Lin, G. J. Greif and J. E. Freedman, Multiple sulfonylurea-sensitive potassium channels: a novel subtype modulated by dopamine, Mol. Pharmacol. 44 (1993), pp. 907-910.

Miki and Seino, 2005 T. Miki and S. Seino, Roles of KATP channels as metabolic sensors in acute metabolic changes, J. Mol. Cell. Cardiol. 38 (2005), pp. 917-925.

Millan et al., 1999 M. J. Millan, M. Brocco, A. Gobert, F. Joly, K. Bervoets, J. Rivet, A. Newman-Tancredi, V. Audinot and S. Maurel, Contrasting mechanisms of action and sensitivity to antipsychotics of phencyclidine versus amphetamine: importance of nucleus accumbens 5-HT2A sites for PCP-induced locomotion in the rat, Eur. J. NeuroSci. 11 (1999), pp. 4419-4432.

Millan et al., 2008 M. J. Millan, F. Loiseau, A. Dekeyne, A. Gobert, G. Flik, T. I. Cremers, J. M. Rivet, D. Sicard, R. Billiras and M. Brocco, S33138 (N-[4-[2-[(3aS, 9bR)-8-cyano-1, 3a, 4, 9b-tetrahydro[1] benzopyrano[3, 4-c]pyrrol-2(3H)-yl)-ethyl]phenyl-acetamide), a preferential dopamine D3 versus D2 receptor antagonist and potential antipsychotic agent: III. Actions in models of therapeutic activity and induction of side effects, J. Pharmacol. Exp. Ther. 324 (2008), pp. 1212-1226.

Miyamoto et al., $2005>$ S. Miyamoto, G. E. Duncan, C. E. Marx and J. A. Lieberman, Treatments for schizophrenia: a critical review of pharmacology and mechanisms of action of antipsychotic drugs, Mol. Psychiatry 10 (2005), pp. 79-104.

Mo et al., 2005 Y. Q. Mo, X. L. Jin, Y. T. Chen, G. Z. Jin and W. X. Shi, Effects of l-stepholidine on forebrain Fos expression: comparison with clozapine and haloperidol, Neuropsychopharmacology 30 (2005), pp. 261-267.

Moghaddam and Homayoun, $2008 \longrightarrow$ B. Moghaddam and H. Homayoun, Divergent plasticity of prefrontal cortex networks, Neuropsychopharmacology 33 (2008), pp. 42-55. 
Natesan et al., 2006 S. Natesan, G. E. Reckless, J. N. Nobrega, P. J. Fletcher and S. Kapur, Dissociation between in vivo occupancy and functional antagonism of dopamine D2 receptors: comparing aripiprazole to other antipsychotics in animal models, Neuropsychopharmacology 31 (2006), pp. 1854-1863.

Paxinos and Watson, $2007 \rightarrow$ G. Paxinos and C. Watson, The rat brain in stereotaxic coordinates, sixth ed, Academic Press, New York (2007).

Robertson and Fibiger, 1992 G. S. Robertson and H. C. Fibiger, Neuroleptics increase c-fos expression in the forebrain: contrasting effects of haloperidol and clozapine, Neuroscience 46 (1992), pp. 315-328.

Robertson et al., 1994 G. S. Robertson, H. Matsumura and H. C. Fibiger, Induction patterns of Fos-like immunoreactivity in the forebrain as predictors of atypical antipsychotic activity, J. Pharmacol. Exp. Ther. 271 (1994), pp. 1058-1066.

Ross et al., 2006 C. A. Ross, R. L. Margolis, S. A. Reading, M. Pletnikov and J. T. Coyle, Neurobiology of schizophrenia, Neuron $\mathbf{5 2}$ (2006), pp. 139-153.

Sotty et al., 2008 F. Sotty, T. Damgaard, L. P. Montezinho, A. Mork, C. K. Olsen, C. Bundgaard and H. Husum, Antipsychotic-like effect of retigabine, a KCNQ potassium channel opener, via modulation of mesolimbic dopaminergic neurotransmission, J. Pharmacol. Exp. Ther. (2008).

Sun et al., 2009 T. Sun, G. Hu and M. Li, Repeated antipsychotic treatment progressively potentiates inhibition on phencyclidineinduced hyperlocomotion, but attenuates inhibition on amphetamine-induced hyperlocomotion: relevance to animal models of antipsychotic drugs, Eur. J. Pharmacol. 602 (2009), pp. 334-342.

Swanson and Schoepp, $2003 \rightarrow$ C. J. Swanson and D. D. Schoepp, A role for noradrenergic transmission in the actions of phencyclidine and the antipsychotic and antistress effects of mGlu2/3 receptor agonists, Ann. N. Y. Acad. Sci. 1003 (2003), pp. 309-317.

Swerdlow et al., 1996 N. R. Swerdlow, V. Bakshi and M. A. Geyer, Seroquel restores sensorimotor gating in phencyclidine-treated rats, J. Pharmacol. Exp. Ther. 279 (1996), pp. 1290-1299.

Swerdlow et al., $2001>$ N. R. Swerdlow, M. A. Geyer and D. L. Braff, Neural circuit regulation of prepulse inhibition of startle in the rat: current knowledge and future challenges, Psychopharmacology (Berl) 156 (2001), pp. 194-215.

Swerdlow et al., $2008 \rightarrow$ N. R. Swerdlow, M. Weber, Y. Qu, G. A. Light and D. L. Braff, Realistic expectations of prepulse inhibition in translational models for schizophrenia research, Psychopharmacology (Berl) 199 (2008), pp. 331-388.

Thomzig et al., 2005 A. Thomzig, G. Laube, H. Pruss and R. W. Veh, Pore-forming subunits of K-ATP channels, Kir6. 1 and Kir6. 2 , display prominent differences in regional and cellular distribution in the rat brain, J. Comp. Neurol. 484 (2005), pp. 313-330.

Valenstein, 1998 E. S. Valenstein, Blaming the Brain: The Truth About Drugs and Mental Health, Free Press, New York (1998), p. xi 292 pp.

Wadenberg and Hicks, $1999>$ M. L. Wadenberg and P. B. Hicks, The conditioned avoidance response test re-evaluated: is it a sensitive test for the detection of potentially atypical antipsychotics?, Neurosci. Biobehav. Rev. 23 (1999), pp. 851-862.
Wang et al., $2004 \rightarrow$ H. Wang, Y. L. Zhang, X. C. Tang, H. S. Feng and $\mathrm{G}$. Hu, Targeting ischemic stroke with a novel opener of ATP-sensitive potassium channels in the brain, Mol. Pharmacol. 66 (2004), pp. 1160-1168.

Wang et al., 2005a $>$ H. Wang, C. L. Long and Y. L. Zhang, A new ATP-sensitive potassium channel opener reduces blood pressure and reverses cardiovascular remodeling in experimental hypertension, J. Pharmacol. Exp. Ther. 312 (2005), pp. 1326-1333.

Wang et al., 2005b H. Wang, Y. L. Zhang and Y. P. Chen, Targeting small arteries of hypertensive status with novel ATP-sensitive potassium channel openers, Curr. Vasc. Pharmacol. 3 (2005), pp. 119-124.

Wang et al., 2005c S. Wang, L. F. Hu, Y. Yang, J. H. Ding and G. $\mathrm{Hu}$, Studies of ATP-sensitive potassium channels on 6-hydroxydopamine and haloperidol rat models of Parkinson's disease: implications for treating Parkinson's disease?, Neuropharmacology 48 (2005), pp. 984-992.

Wang et al., 2006 S. Wang, L. F. Hu, Y. Zhang, T. Sun, Y. H. Sun, S. Y. Liu, J. H. Ding, J. Wu and G. Hu, Effects of systemic administration of iptakalim on extracellular neurotransmitter levels in the striatum of unilateral 6-hydroxydopamine-lesioned rats, Neuropsychopharmacology 31 (2006), pp. 933-940.

Yang et al., 2006a J. Yang, L. F. Hu, X. Liu, F. Zhou, J. H. Ding and G. Hu, Effects of iptakalim on extracellular glutamate and dopamine levels in the striatum of unilateral 6-hydroxydopamine-lesioned rats: a microdialysis study, Life Sci. 78 (2006), pp. 1940-1944.

Yang et al., 2006b - Y. J. Yang, Q. M. Wang, L. F. Hu, X. L. Sun, J. H. Ding and G. Hu, Iptakalim alleviated the increase of extracellular dopamine and glutamate induced by 1-methyl-4-phenylpyridinium ion in rat striatum, Neurosci. Lett. 404 (2006), pp. 187-190.

Yang et al., 2008 Y. J. Yang, S. Zhang, J. H. Ding, F. Zhou and G. $\mathrm{Hu}$, Iptakalim protects against MPP+-induced degeneration of dopaminergic neurons in association with astrocyte activation, Int. J. Neuropsychopharmacol. (2008), pp. 1-11.

Zhang et al., $2007 \rightarrow$ S. Zhang, F. Zhou, J. H. Ding, X. Q. Zhou, X. L. Sun and G. Hu, ATP-sensitive potassium channel opener iptakalim protects against MPP-induced astrocytic apoptosis via mitochondria and mitogen-activated protein kinase signal pathways, J. Neurochem. 103 (2007), pp. 569-579.

Zhao and Li $2010>$ C. Zhao and M. Li, C-Fos identification of neuroanatomical sites associated with haloperidol and clozapine disruption of maternal behavior in the rat, Neuroscience 166 (2010), pp. 1043-1055.

Zhou et al., 2007 F. Zhou, J. Y. Wu, X. L. Sun, H. H. Yao, J. H. Ding and G. Hu, Iptakalim alleviates rotenone-induced degeneration of dopaminergic neurons through inhibiting microglia-mediated neuroinflammation, Neuropsychopharmacology 32 (2007), pp. 2570-2580.

Zweifel et al., 2009 L. S. Zweifel, J. G. Parker, C. J. Lobb, A. Rainwater, V. Z. Wall, J. P. Fadok, M. Darvas, M. J. Kim, S. J. Mizumori, C. A. Paladini, P. E. Phillips and R. D. Palmiter, Disruption of NMDAR-dependent burst firing by dopamine neurons provides selective assessment of phasic dopamine-dependent behavior, Proc. Natl. Acad. Sci. U. S. A. 106 (2009), pp. 7281-7288. 